\title{
Filling of chrysotile nanotubes with metals
}

\author{
C. Métraux and B. Grobéty \\ University of Fribourg, Institute of Mineralogy and Petrography, 1700 Fribourg, Switzerland \\ P. Ulmer \\ Eidgenössishe Technische Hochschule Zürich, Institute of Mineralogy and Petrography, 8052 \\ Zürich, Switzerland
}

(Received 5 September 2001; accepted 19 February 2002)

\begin{abstract}
Nanowires were produced by injection of molten $\mathrm{Hg}$ and $\mathrm{Pb}$ into chrysotile nanotubes. The breakdown of chrysotile and the surface tension of the molten metals are the limiting factors for the filling procedure. The thermal stability of chrysotile nanotubes was investigated by infrared spectrometry, thermogravimetry, differential thermal analysis, and x-ray diffraction analyses. For short-term thermal annealing (30 min) the tube morphology remains stable up to $700{ }^{\circ} \mathrm{C}$. The high surface tension of both molten $\mathrm{Pb}$ and $\mathrm{Hg}\left(\gamma^{\mathrm{LV}}>200 \mathrm{mN} / \mathrm{m}\right)$ requires external pressure for the melts to penetrate into the tubes. Filling of the tubes was achieved under high pressure and high temperature conditions compatible with the stability range for chrysotile determined in the annealing experiments. Transmission electron microscopy observations confirmed high filling yields for both metals. Almost all nanotubes were partially filled with lead. The length of continuous wires ranged from tens to hundreds of nanometers. Additional experiments with tin were not successful.
\end{abstract}

\section{INTRODUCTION}

The potential applications for nano-sized, tube-shaped components includes wires, wire-templates, microreactors, hydraulic tubes, and gas storage devices among others. The most promising contender for such applications are synthetic carbon nanotubes. Other layered materials known to form nanotubes are boron nitride, ${ }^{1}$ molybdenum disulfide, ${ }^{2}$ and tungsten disulfide. ${ }^{2}$ A naturally occurring, nano-sized, tube-shaped phase is the silicate mineral chrysotile, $\mathrm{Mg}_{3} \mathrm{Si}_{2} \mathrm{O}_{5}(\mathrm{OH})_{4}$, which may represent an alternative to carbon nanotubes for certain applications such as the manufacture of nanowires. The structure of chrysotile ${ }^{3}$ consists of wrapped sheets composed of a layer of tetrahedrally coordinated silicon cations and a layer of octahedrally coordinated magnesium cations, which can be substituted by aluminum and iron. Aluminum can also be present in the tetrahedral sheet instead of silicon (Tschermak's substitution). Chrysotile is common in hydrothermally altered ultramafic rocks and is easy to extract in large quantities. The tubes have an outer diameter ranging from 10 to $50 \mathrm{~nm}$ and an inner diameter between 1 and $10 \mathrm{~nm}$. The tube walls are always multilayered. ${ }^{4}$ Just as for carbon nanotubes, different wrapping schemes are known. ${ }^{5}$ The most frequent polytypes are normal chrysotile with a fiber axis perpendicular to the [010] direction and parachrysotile with a fiber axis in the [010] direction. ${ }^{5}$ Cylindrical, spiral and multilayer wrapping is found for both chrysotile polytypes. ${ }^{5}$ The chrysotile nanotubes differ from the carbon nanotubes in some important physical parameters, e.g., they are nonconducting, they have lower mechanical strength, their length can reach the millimeter range, and they are always uncapped. ${ }^{6}$

Some potential applications of nanotubes, such as the manufacture of nanowires, require access to the inner cavity. ${ }^{7}$ Carbon nanotubes have been filled by wet chemistry using capillary suction. ${ }^{8-12}$ Chrysotile nanotubes have been filled with metals melting at low temperature, such as $\mathrm{Hg},{ }^{13,14} \mathrm{Bi},{ }^{14} \mathrm{Te},{ }^{15} \mathrm{Se},{ }^{15}$ and with semiconductor materials using both high-pressure techniques and chemical vapor deposition (CVD), ${ }^{14-18}$ but only few experimental details have been given. The limited temperature stability of the chrysotile morphology and its possible influence on the filling process has not been addressed. The structural breakdown of chrysotile, e.g., the transformation of the walls, has been addressed by many authors, but not in relationship to the filling of the nanotubes. ${ }^{19-22}$ The phase evolution during heating is well documented, but information on the morphological changes is scarce. ${ }^{23}$ This paper presents not only the structural, but also the morphological evolution of chrysotile nanotubes during short-term, high-temperature annealing. This information was used to design hightemperature injection experiments with $\mathrm{Pb}$ and $\mathrm{Sn}$. In the liquid state, these metals have surface tension, which does not allow filling by capillary suction. An outer pressure must therefore be applied to force the melts into the nanotubes. ${ }^{9}$ As a pressurizing device, an end-loaded 
piston cylinder apparatus was used for the first time. These experiments were the first attempts to fill chrysotile tubes close to the beginning of dehydration and the metals used have higher melting temperatures than all materials used in previous experiments. ${ }^{13-18}$

\section{EXPERIMENTAL}

\section{A. Starting materials}

All experiments were performed with the same chrysotile specimen from an unspecified location in Pennsylvania. High-purity metal liquid and powders were used for the filling experiments: $\mathrm{Hg}$ (Micromeritics, West Lafayette, IN), Pb (Riedel-de Haën, Seelze, Germany), and Sn (Fluka, Buchs, Switzerland).

\section{B. Thermal analysis of chrysotile nanotubes}

The water release of the chrysotile sample as function of heating temperature was monitored with a LECO infrared (IR) spectrometer, model RC-412 (St. Louis, MO). The IR absorption of the gas was measured continuously and quantitatively for absorption bands characteristic of $\mathrm{H}_{2} \mathrm{O}$ and $\mathrm{CO}_{2}$. The onset of dehydration was determined by heating the samples $(0.2 \mathrm{~g})$ from 100 to $700{ }^{\circ} \mathrm{C}$ at a rate of $20^{\circ} \mathrm{C} / \mathrm{min}$. To quantify the weight percent of water lost by dehydroxilation at a fixed temperature, samples were first annealed at $450{ }^{\circ} \mathrm{C}$ for $30 \mathrm{~min}$ to eliminate adsorbed water and then heated to the temperature of interest. The water release was monitored for $30 \mathrm{~min}$. The in situ IR analyses were complemented by thermogravimetry and differential thermal analyses (DTA-TGA). Measurements from room temperature to $1100{ }^{\circ} \mathrm{C}$ were performed using a Mettler-Toledo model TGA/SDTA.851 (Columbus, OH) at a heating rate of $10{ }^{\circ} \mathrm{C} / \mathrm{min}$. X-ray diffraction (XRD) patterns were taken on sample powders using a PW1800 Philips system (Eidenhoven, The Netherlands) equipped with a $\mathrm{Cu} \mathrm{K}_{\alpha} \mathrm{X}-$ ray tube, a graphite monochromator, and a variable receiving slit. The data were collected in step scanning mode from $5^{\circ}$ to $75^{\circ}(2 \theta)$, with a step size of $0.02^{\circ}(2 \theta)$ and a counting rate of $2 \mathrm{~s} / \mathrm{step}$.

\section{Filling experiments with $\mathrm{Hg}$}

Chrysotile nanotubes were placed in a Micromeritics model Autopore II $9220 \mathrm{Hg}$-porosimeter (West Lafayette, IN). The sample holder containing the nanotubes was evacuated at $50 \mu \mathrm{m} \mathrm{Hg}$, and then $\mathrm{Hg}$ was injected. The pressure necessary to fill capillaries by fluids is given by the Young-Laplace equation:

$$
\Delta P=\frac{2 \gamma \cos \theta}{r},
$$

where $\gamma$ and $\theta$ are the surface tension and the wetting angle of the liquid, respectively, and $r$ is the radius of the capillary. The minimum pressure to fill a nanocapillary with a 5-nm diameter (typical inner diameter of chrysotile nanotubes) with $\mathrm{Hg}$ is $2.43 \mathrm{Kbar}$. This value is obtained for a constant contact angle of $130^{\circ}$ and for a surface tension (against vacuum) of $473 \mathrm{mN} / \mathrm{m}$ at $25^{\circ} \mathrm{C}$ $\left(\gamma^{\mathrm{LV}}\right.$ at the melting temperature of $\mathrm{Hg}: 484 \mathrm{mN} / \mathrm{m}$; $\left.-\mathrm{d} \gamma^{\mathrm{LV}} / \mathrm{d} T: 0.18 \mathrm{mN} / \mathrm{mK}\right) .{ }^{24}$ The sign of the pressure derivative of the surface tension is very much dependent on the vapor phase with which the liquid is in contact. ${ }^{25}$ For an inert gas $\mathrm{d} \gamma^{\mathrm{LV}} / \mathrm{d} P$ is positive, but experiments have shown that with the exception of helium, most other gases adsorb onto the liquid surface and the pressure derivative becomes negative, ${ }^{26}$ which is probably also the case for the gas (air, water vapor) surrounding chrysotile tubes in the container. The pressure of $4 \mathrm{Kbar}$ used in the experiments should, therefore, be sufficient to fill all tubes down to the smallest diameters. The pressure was increased in variable steps. As soon as 4 Kbar was reached, the pressure was immediately released to atmospheric conditions. Finally, the chrysotile nanotubes were extracted from the sample holder, mechanically ground, placed in ethanol, and ultrasonically dispersed.

\section{Filling experiments with $\mathrm{Pb}$ and $\mathrm{Sn}$}

The metals lead and tin have melting temperatures, which, at ambient pressure, are below the breakdown temperature of the tube morphology of chrysotile. The surface tensions of the two metals at melting temperature are similar to the surface tension of mercury, e.g., $460 \mathrm{mN} / \mathrm{m}$ at $327.4{ }^{\circ} \mathrm{C}$ for lead and $570 \mathrm{mN} / \mathrm{m}$ at $231.9^{\circ} \mathrm{C}$ for tin. ${ }^{24}$ Assuming the worst case for the wetting angle, e.g., $180^{\circ}$, the minimum filling pressures at the melting temperature are $3.68 \mathrm{Kbar}$ for $\mathrm{Pb}$ and $4.56 \mathrm{Kbar}$ for $\mathrm{Sn}$. The experiments were performed in a Johannes-type piston-cylinder pressure apparatus at a pressure of $10 \mathrm{Kbar}$ and a temperature of $440{ }^{\circ} \mathrm{C}$, well above the calculated minimum pressures and below the onset temperature of dehydroxilation of chrysotile (see results). Because pressure raises the melting point of metals, experimental temperatures well above the melting point at room conditions were chosen. ${ }^{27}$ The true minimum filling pressure is probably lower than the values indicated above because the temperature dependence of the surface tension is negative for both metals $(\mathrm{Pb}$ : $-0.11 \mathrm{mN} / \mathrm{mK}$; $\mathrm{Sn}:-0.10 \mathrm{mN} / \mathrm{mK}),{ }^{24}$ and also the pressure derivatives of the surface tension are most likely negative. ${ }^{26}$

The chrysotile nanotubes and pure metal powder $(\mathrm{Pb}$, $\mathrm{Sn})$ were mechanically ground together and put in a BN capsule, which was placed inside a Pt capsule $(3 \mathrm{~mm}$ in diameter, $10 \mathrm{~mm}$ long). The material was first pressurized, then heated to $440{ }^{\circ} \mathrm{C}$ and annealed for $15 \mathrm{~min}$. The mixture was subsequently quenched to room temperature to freeze the metal within the nanotubes. The quenching rate was on the order of $200{ }^{\circ} \mathrm{C} / \mathrm{s}$ down to $200{ }^{\circ} \mathrm{C}$, and then slower to room temperature. Finally pressure was 
lowered to atmospheric conditions. Nanotubes were extracted from the BN/Pt capsules, mechanically ground, placed in ethanol, and ultrasonically dispersed.

\section{E. Transmission electron microscopy}

A drop of the ethanol dispersion with the run products was put on a holey carbon grid and dried in air. Transmission electron microscopy (TEM) studies were performed using a Philips CM10 and a Philips CM200 operated at 100 and $200 \mathrm{kV}$, respectively. The mercuryfilled samples were analyzed at $100 \mathrm{kV}$ and all other samples were analyzed at $200 \mathrm{kV}$. The radiation damage in chrysotile was probably due to radiolytic processes. The loss of hydrogen through a knock-on process destabilized the structure, which transforms to an amorphous phase. Heating of the sample had only a secondary influence. The increase in acceleration voltage reduced this effect and allowed high-resolution TEM (HRTEM) imaging of the lead and tin samples. Under illumination conditions necessary for high-resolution imaging, chrysotile survives for approximately $30 \mathrm{~s}$.

\section{RESULTS AND DISCUSSION}

\section{A. Thermal properties of chrysotile nanotubes}

XRD patterns (Fig. 1) of the Pennsylvanian sample are compatible with the normal chrysotile polytype. Two transformations of these nanotubes can be distinguished in DTA runs up to $1100{ }^{\circ} \mathrm{C}$ (Fig. 2). A broad endothermic peak, centered at a temperature of $700{ }^{\circ} \mathrm{C}$, was attributed to the departure of structural water leading to an amorphization of the material. The amorphous nature of the initial breakdown product was confirmed by the XRD pattern of a sample quenched from the same temperature (Fig. 1). The second, sharp exothermic DTA peak at about $820{ }^{\circ} \mathrm{C}$ was attributed to the crystallization of the $\mathrm{Mg}$-silicate phases forsterite $\mathrm{Mg}_{2} \mathrm{SiO}_{4}$ and enstatite $\mathrm{MgSiO}_{3}$ as inferred from XRD patterns of quenched

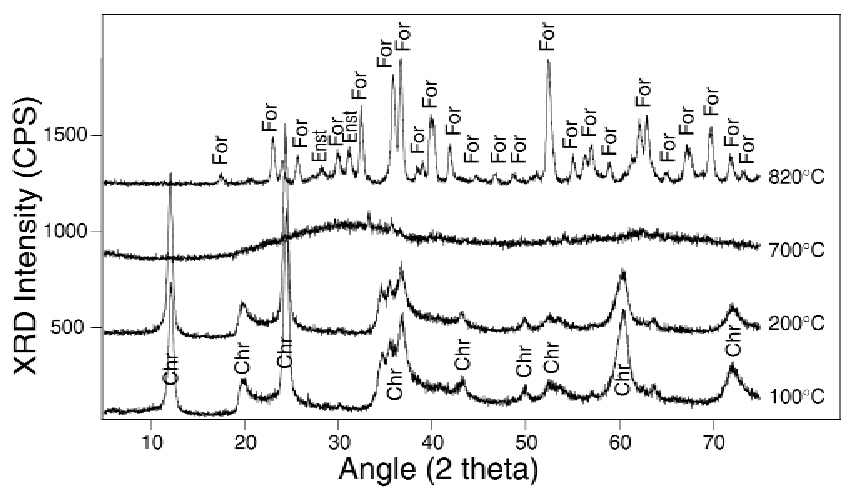

FIG. 1. XRD patterns of chrysotile nanotubes after annealing for 10 min in dry air. samples (Fig. 1). The total weight loss measured by TGA was $15.2 \mathrm{wt} \%$, which is about $2.5 \mathrm{wt} \%$ above the water quantity expected from the hydroxyl concentration in stoichiometric chrysotile.

The continuous in situ IR scans on as-received chrysotile show three peaks. The first two peaks at about 100 and $200{ }^{\circ} \mathrm{C}$ of the dehydroxilation curve (Fig. 3) were attributed to water desorbed from the surface of the chrysotile nanotubes and/or released from the interior of the tubes, since no structural changes were detected by XRD analysis on fibers treated at the same temperatures (Fig. 1). The onset of the third, broad dehydroxilation peak was around $470{ }^{\circ} \mathrm{C}$. This peak was linked to a loss of crystallinity indicated by a net decrease of the maximum intensity and a broadening of XRD peaks (Fig. 4).

Samples of chrysotile first annealed at $450{ }^{\circ} \mathrm{C}$ for 30 min to eliminate adsorbed water and then heated at the temperature of interest and annealed for an additional 30 min show that for temperatures $<650{ }^{\circ} \mathrm{C}$, dewatering will not go to completion. The total amount of water lost during these additional $30 \mathrm{~min}$ of thermal treatment increases with annealing temperature (Fig. 5). The water loss after $30 \mathrm{~min}$ at $550{ }^{\circ} \mathrm{C}$ corresponds only to $33 \%$ of the stoichiometric hydroxyl content, whereas at $600{ }^{\circ} \mathrm{C}$ it corresponds to $79 \%$.

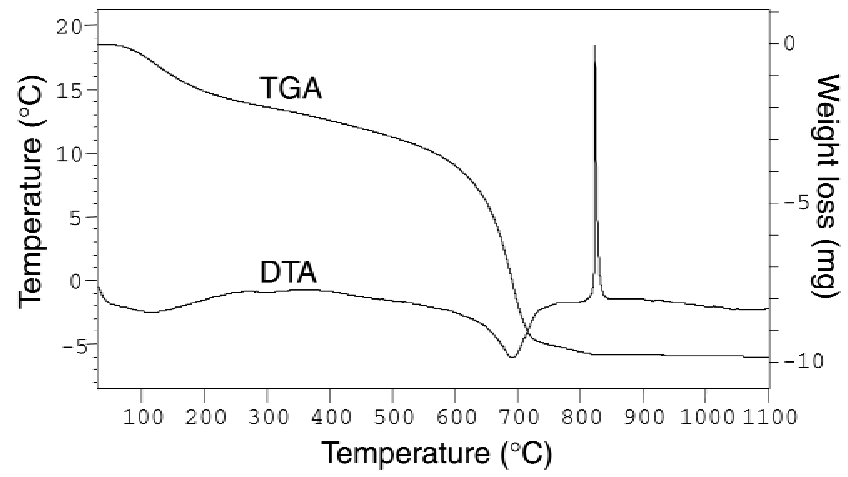

FIG. 2. TG-DTA curves of chrysotile nanotubes.

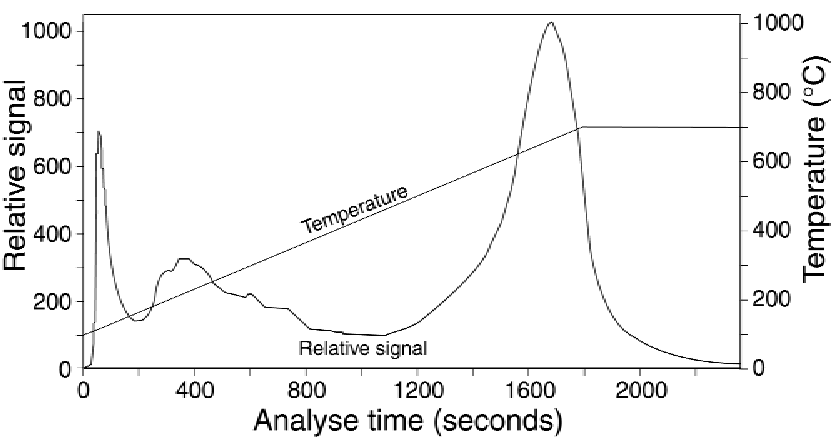

FIG. 3. Water release of chrysotile nanotubes as function of temperature measured through continuous in situ IR of the released gases. 
The XRD patterns (Fig. 1) of samples annealed at $700{ }^{\circ} \mathrm{C}$ are characteristic for amorphous material, but bright-field (BF) TEM pictures (Fig. 6) show that the tubular morphology persisted despite the amorphization of the walls. This temperature is approximately $200{ }^{\circ} \mathrm{C}$ higher than the breakdown temperature of chrysotile to forsterite + water in long-term ambient pressure experiments ( $\geqslant 1$ day). ${ }^{20}$ In experiments run at $750{ }^{\circ} \mathrm{C}$ during $30 \mathrm{~min}$ the tubes collapsed. For short-term experiments (30 min) a temperature of $700{ }^{\circ} \mathrm{C}$ is therefore the maximum temperature for which filling is possible. The experimental conditions used for the lead and tin filling experiments, (e.g., $440{ }^{\circ} \mathrm{C}, 10 \mathrm{Kbar}$ at a heating rate of $50{ }^{\circ} \mathrm{C} / \mathrm{min}$ ) guarantee the persistence of the tube morphology through the entire experiment duration. The amorphous $\mathrm{Si}-\mathrm{Mg}$-oxide nanotubes are more stable than the crystallized tubes under the electron beam irradiation. The absence of hydrogen in the amorphous walls lowers considerably the probability of knock-on radiolytic processes.

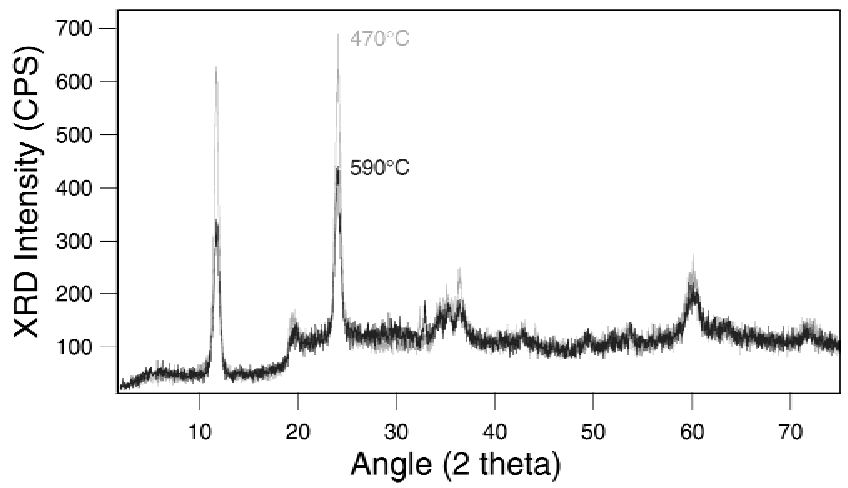

FIG. 4. XRD patterns of chrysotile nanotubes after annealing for 10 min at 470 and $590^{\circ} \mathrm{C}$ in dry air.

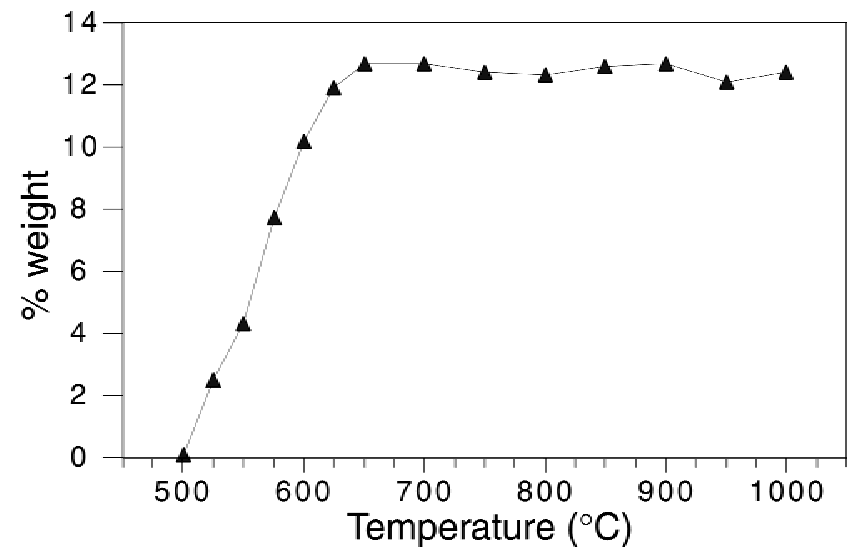

FIG. 5. Amount of water released as function of annealing temperature.

\section{B. Filling experiments with $\mathrm{Hg}$}

TEM observations (Fig. 7) show that the chrysotile nanotubes are partially filled with liquid mercury. The contrast difference between empty and metal-filled parts is noticeable. The average diameter of the $\mathrm{Hg}$ nanowires is $5 \mathrm{~nm}$. Liquid mercury moves rapidly under the electron beam, making it difficult to estimate

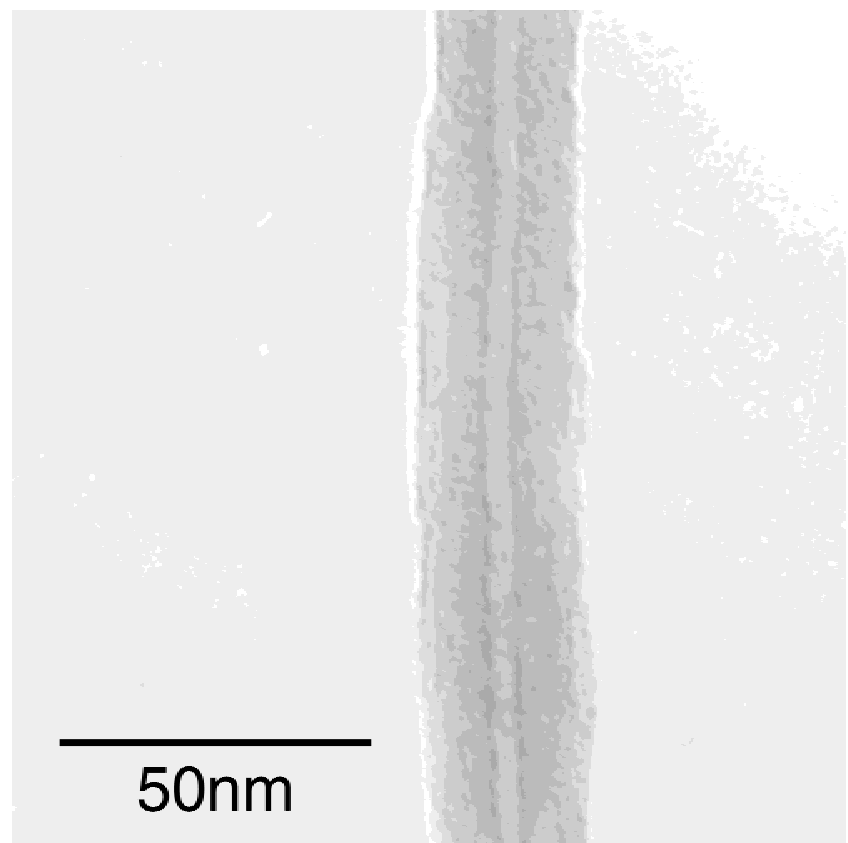

FIG. 6. BF TEM image of an amorphous nanotube after annealing at $700{ }^{\circ} \mathrm{C}$.

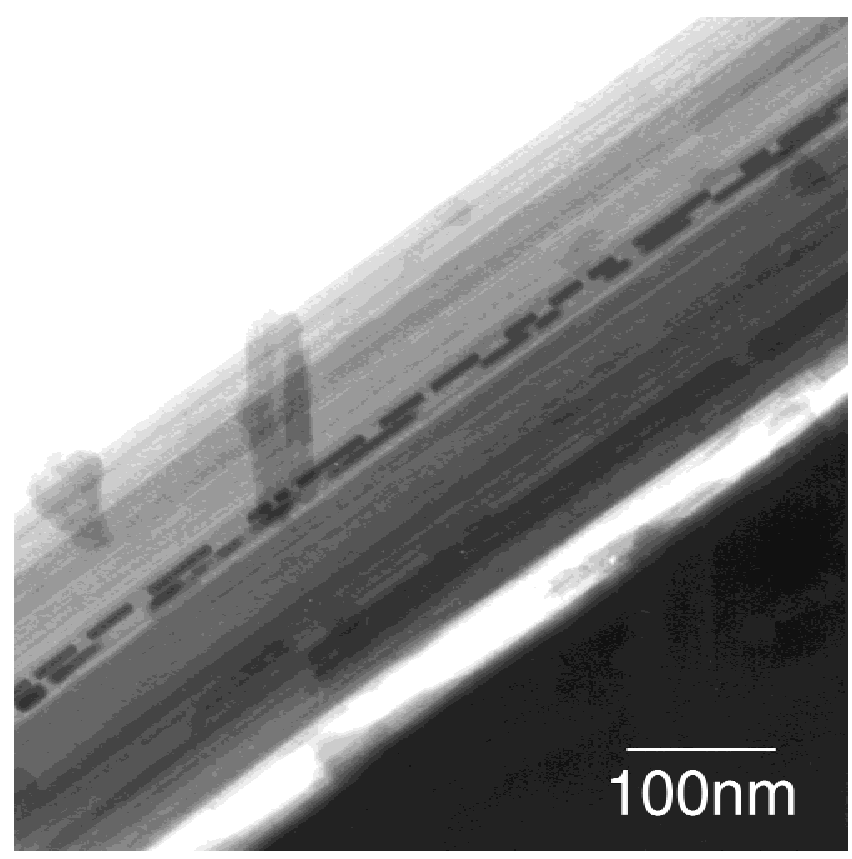

FIG. 7. BF image of a bundle of chrysotile nanotubes. Two nanotubes are partially filled with mercury nanowires $5 \mathrm{~nm}$ in diameter. 
filling efficiency and to measure the length of individual $\mathrm{Hg}$ nanowires. The maximum $\mathrm{Hg}$-filled length observed was about $350 \mathrm{~nm}$. $\mathrm{Hg}$ was present in the inner tubes of almost all fibers with a length $>1 \mu \mathrm{m}$, whereas most of the short fibers were empty. This experiment confirmed that the majority of the chrysotile tubes were unclogged and allow the penetration of suitable liquids.

\section{Filling experiments with $\mathrm{Pb}$ and $\mathrm{Sn}$}

The duration and temperature of the experiments were chosen based on the results obtained in the previous dewatering experiments. Nanotubes pressurized at $10 \mathrm{Kbar}$ and heated at $440{ }^{\circ} \mathrm{C}$ still showed crystalline walls (Fig. 8). In the experiment with $\mathrm{Pb}$ all chrysotile nanotubes contained lead. The yield for individual tubes was variable and ranged from $10 \%$ to $70 \%$ (Fig. 9). No discrepancies in the degree of filling were noticed between long and short fibers. Many chrysotile fiber surfaces were covered with lead droplets. The wetting angle was clearly $>90^{\circ}$. The quenching of the experimental charge seemed to effectively freeze the molten lead inside the tubes. Under electron beam irradiation, however, the metal started to migrate along the tube, as can be seen in two images taken in intervals of $10 \mathrm{~s}$ [Figs. 10(a) and 10(b)]. The lowering of the melting temperature for nano-sized particles relative to the corresponding bulk material ${ }^{24}$ and the heating of the metal through the electron beam are likely, but not the only explanations for this behavior. The particles attached to the outside wall of the fiber had similar or even smaller diameters, but

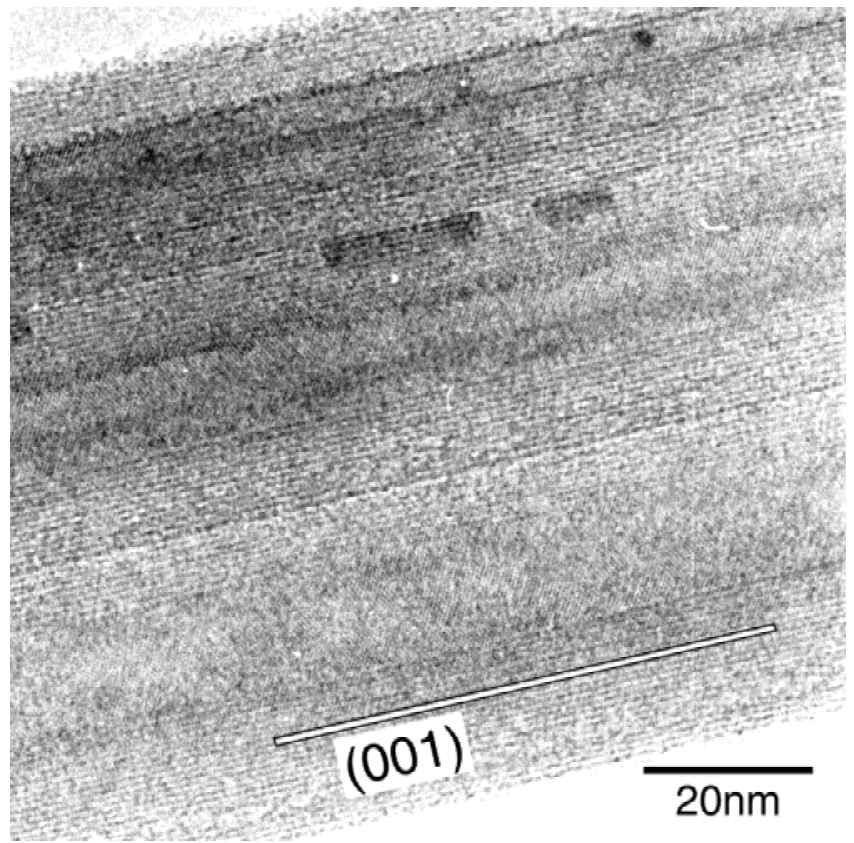

FIG. 8. HRTEM image showing a bundle of chrysotile nanotubes which were heated at $440{ }^{\circ} \mathrm{C}$ and pressurized at $10 \mathrm{Kbar}$. The $7.3 \AA$ (001) fringes in the tube walls are visible. they remained solid and did not move, also after intense electron irradiation [left arrow in Figs. 10(a) and 10(b)]. A possible explanation for this different behavior is the fact that the lead in the interior of the tube was protected from contact with the atmosphere. The lead particles outside the tubes in contrast, could easily be oxidized during sample handling. The melting temperature of the different lead oxides is approximately twice that of metallic lead. An alternative cause could be the influence of hydrogen atoms knocked off the tube walls by impinging electrons. Hydrogen, which may concentrate in the interior of the tube, is known to soften metal-metal bonds and to lower the melting temperature of metal clusters. ${ }^{28}$ Moreover, lead hydride is known to be a very unstable compound. Continuous filling from one extremity to the other for several tubes was noticed, but fast migration and segregation of $\mathrm{Pb}$ nanowires along the nanocapillaries impeded imaging of such nanowires.

Although the physicochemical parameters of tin are not very different from lead, the interior of the chrysotile tubes extracted from the charge were all empty. Only a few nanotubes seemed to contain tin close to the tube end. Solid tin droplets covered the outer surfaces of fibers found close to bulk tin fragments (Fig. 11), a sign that tin was in the molten state and in contact with the fibers during the experiment. In contrast to lead, tin was stable under the electron beam. The droplet shape and the contact angle, which was always $<90^{\circ}$, represent, therefore, the values frozen at $10 \mathrm{Kbar}$ and $440{ }^{\circ} \mathrm{C}$. A possible reason for the discrepancy in the filling behavior between $\mathrm{Pb}$ and $\mathrm{Sn}$ is a difference in the viscosity of the melts at the experimental conditions.

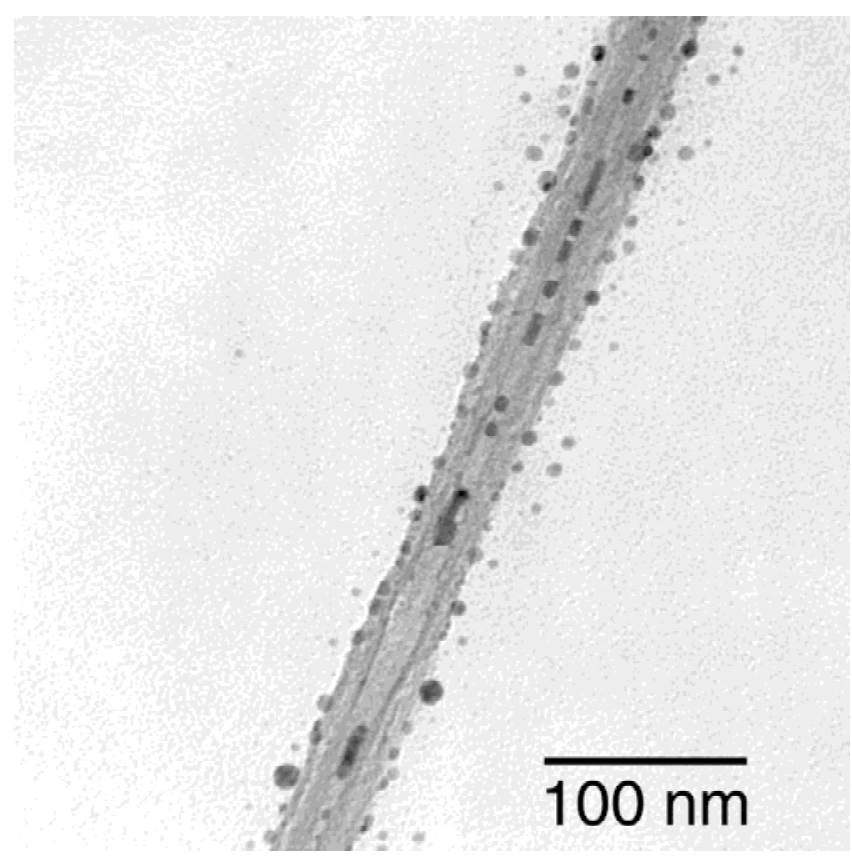

FIG. 9. BF image of an isolated chrysotile nanotube with a tube diameter of $5 \mathrm{~nm}$ partially filled with lead. 

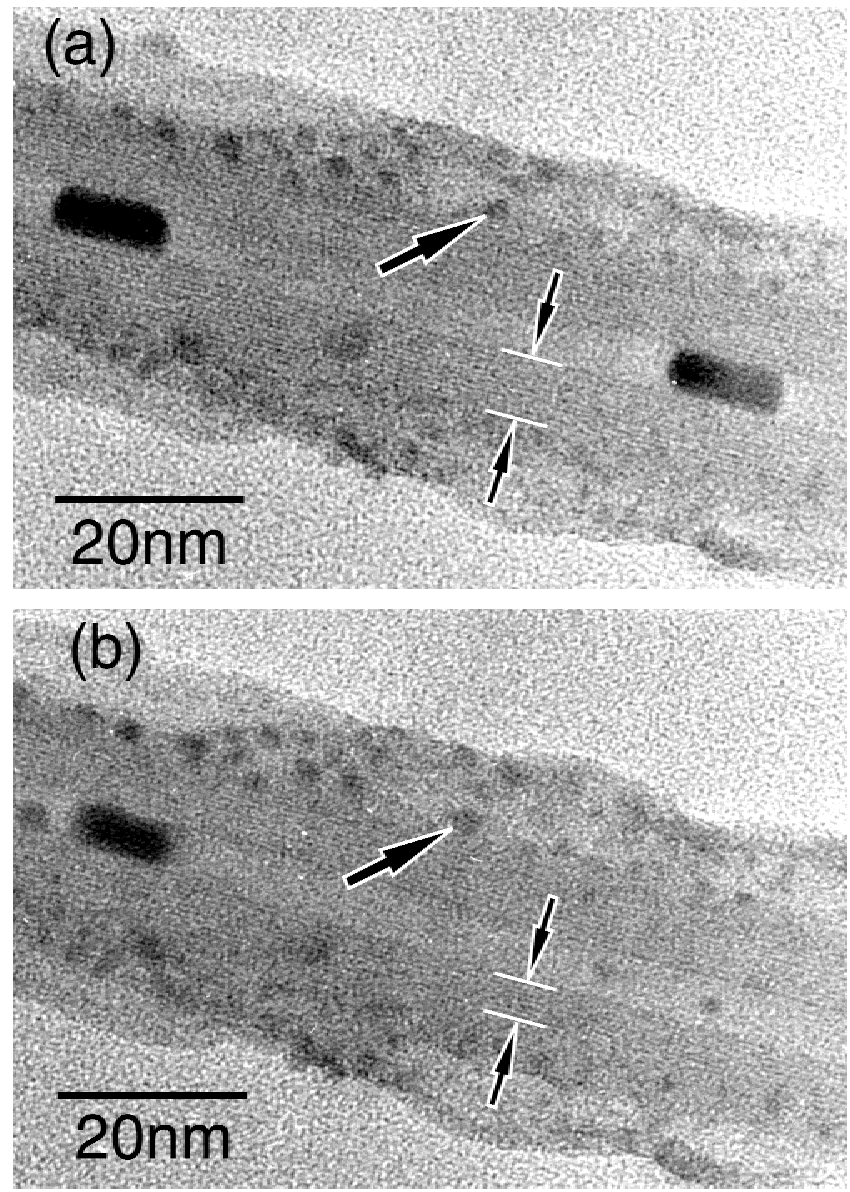

FIG. 10. TEM images recorded at an interval of 10 seconds. The electron beam irradiation induces migration of lead nanowires. Solid $\mathrm{Pb}$ droplets are attached to the tube and remain immobile (see left arrow). Amorphization progress caused by electron irradiation is visible as disappearance of lattice fringes (see right arrows).

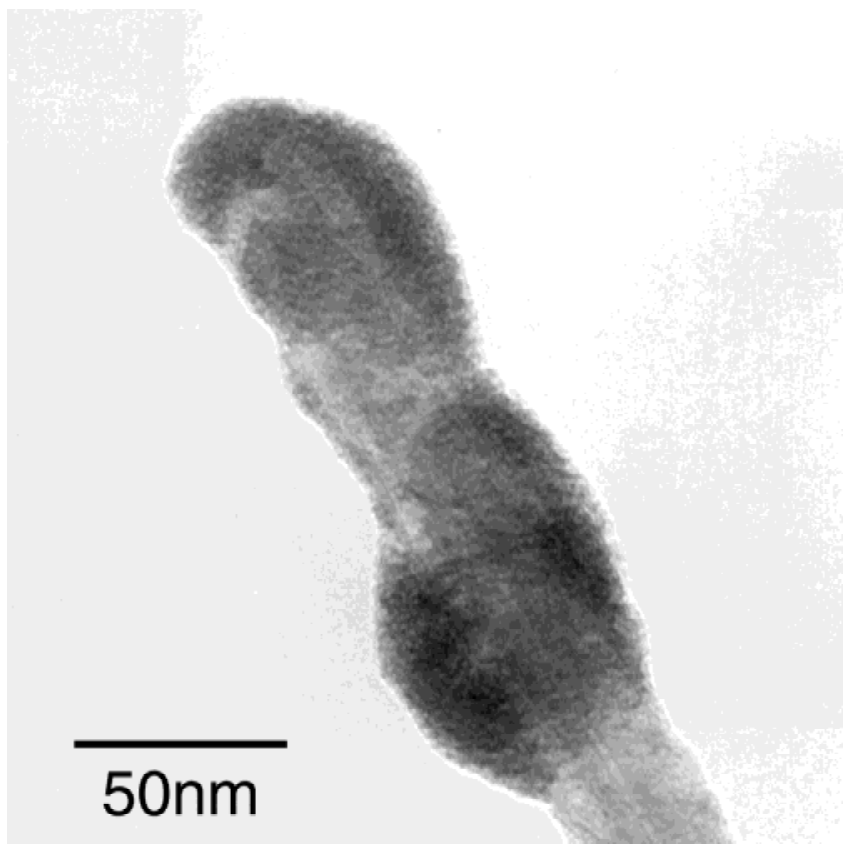

FIG. 11. BF image of solid Sn droplets wetting a chrysotile nanotube.

\section{CONCLUSIONS}

The high-pressure and high-temperature technique is a suitable method to fill nanotubes with high surface tension metals. One-hundred percent of the nanotubes were partially filled with lead. Based on the survival of the chrysotile morphology up to $700{ }^{\circ} \mathrm{C}$, experiments with metals and alloys with higher melting temperature than $\mathrm{Pb}$ and $\mathrm{Sn}$, e.g., $\mathrm{Al}$ and $\mathrm{Cu}-\mathrm{Sn}$ alloys, are in progress. $\mathrm{In}$ these experiments the filling process will be influenced by the simultaneous dehydroxilation of the tube walls.

Pressures used in this study were systematically higher than theoretically calculated ones. Experiments at lower pressures are planed which will allow the use of larger pressure containers. The same technique may also be used to fill multiwalled carbon nanotubes and singlewalled carbon nanotubes, which have a wider morphological stability range than chrysotile. Removing the phyllosilicate layers of chrysotile nanotubes may be an interesting way to produce metal nanowires of welldefined radius and length. Acidic treatment of the metalfilled chrysotile nanotubes is a possible route to reach this goal.

\section{ACKNOWLEDGMENTS}

We thank A. Häfner at the Eidgenössiche Technische Hochschule Zürich for technical support on the pistoncylinder apparatus and M. Dadras at the Swiss Center for Electronics and Microtechnology (CSEM) for assistance with TEM investigations and useful discussions.

\section{REFERENCES}

1. N.G. Chopra, H. Luyken, V.H. Crespi, K. Cherrey, A. Zettl, and M.L. Cohen, Science 269, 966 (1995).

2. M. Nath, A. Govindaraj, and C.N.R. Rao, Adv. Mater. 13, 283 (2001).

3. E.J.W. Whittaker, Acta Cryst. 9, 855 (1956).

4. K. Yada, Acta Cryst. 27, 659 (1971).

5. K. Yada, Acta Cryst. 23, 704 (1967).

6. P.J.F. Harris, Carbon Nanotubes and Related Structures, New Materials for the Twenty-first Century (Cambridge University Press, Cambridge, United Kingdom, 1999).

7. Z.L. Zhang, B. Li, Z.J. Shi, Z.N. Gu, Z.Q. Xue, and L.M. Peng, J. Mater. Res. 15, 2658 (2000).

8. P.M. Ajayan and S. Iijima, Nature 361, 333 (1993).

9. E. Dujardin, T.W. Ebbesen, H. Hiura, and K. Tanigaki, Science 265, 1850 (1994).

10. S.C. Tsang, Y.K. Chen, P.J.F. Harris, and M.L.H. Green, Nature 372, 159 (1994).

11. J. Sloan, D.M. Wright, H.G. Woo, S. Bailey, G. Brown, A.P.E. York, K.S. Coleman, J.L. Hutchison, and M.L.H. Green, J. Chem. Soc., Chem. Commun. 699-700, 699 (1999).

12. M. Terrones, N. Grobert, W.K. Hsu, Y.Q. Zhu, W.B. Hu, H. Terrones, J.P. Hare, H.W. Kraut, and D.R.M. Walton, Mater. Res. Bull. 24, 43 (1999).

13. V.N. Bogomolov and Y.A. Kumzerov, JETP Lett. 21, 198 (1975). 
14. M.S. Ivanova, Y.A. Kumzerov, V.V. Poborchii, Y.V. Ulashkevich, and V.V. Zhuravlev, Microporous Mater. 4, 319 (1995).

15. S.G. Romanov and C.M. Sotomayer Torres, in Nanoscale Science and Technology, edited by N. Garcia (Kluwer Academic Publishers, Dordrecht, The Netherlands, 1998), pp. 255-270.

16. V.V. Poborchii, M.S. Ivanova, and I.A. Salmantina, Superlattices Microstruct. 16, 133 (1994).

17. S.G. Romanov, C.M. Sotomayer Torres, H.M. Yates, M.E. Pemble, V. Butko, and V. Tretijakov, J. Appl. Phys. 82, 380 (1997).

18. E.A. Zhukov, H.M. Yates, M.E. Pemble, C.M. Sotomayor Torres, and S.G. Romanov, Superlattices Microstruct. 27, 571 (2000).

19. G.W. Brindley and J. Zussman, Amer. Min. 42, 461 (1957).

20. M.C. Ball and H.F.W. Taylor, Min. Mag. 33, 467 (1963).
21. G.W. Brindley and R. Hayami, Clays \& Clay Minerals 34, 35 (1964).

22. G.W. Brindley and R. Hayami, Min. Mag. 35, 189 (1965).

23. H. De Souza Santos and K. Yada, Clays Clay Min. 27, 161 (1979).

24. J.M. Howe, Interfaces in Materials (Wiley, New York, 1997).

25. I. Vavruch, J. Colloid Interface Sci. 169, 249 (1995).

26. G.J. Hills and H.J. Høiland, J. Colloid Interface Sci. 99, 463 (1984).

27. Z. Wang, P. Lazor, and S.K. Saxena, Phys. B: Condens. Matter 293, 408 (2001)

28. H. Grönbeck, D. Tomanek, S.G. Kim, and A. Rosen, Z. Phys. D40, 469 (1997). 